\title{
Analysis of cartilage wear particles in equine joints and their relationship to several joint diseases
}

\author{
Ticiana Meireles Sousa, Antonio de Pádua Lima und Bodo Hertsch \\ Klinik für Pferde, Allgemeine Chirurgie und Radiologie der Freie Universität Berlin
}

\begin{abstract}
Summary
Early diagnosis of joint disease, especially degenerative joint disease, represents a great challenge to equine practitioners around the world. It was suggested that the presence of cartilage fragments in the synovial fluid could provide an indication of biomechanically deficient articular surfaces. The main objective of this study was to compare the presence of clinical signs of the joint disease with the presence, number, size and amount of cartilage fragments found in synovial fluid. One hundred and sixteen synovial fluid samples from sixty-seven horses were analysed for presence, number and size of cartilage wear particles. The material was centrifugated and prepared for microscopic examination. The animals presented different joint affections and were divided into six groups according to the presence of clinical signs, radiographic and arthroscopic alterations. There was a significant correlation between cartilage debris and lesions of the articular surfaces in horses with osteoarthritis and osteochondritis dissecans. Acute cases, such as septic arthritis, showed no significant number of cartilage fragments. This is a simple, minimal invasive method that could allow a better assessment of the degenerative joint disease. It also has great potential to provide a good assessment of the progress of osteoarthritis, long-term prognosis and the evaluation of therapeutic regimes without repeated surgical intervention.
\end{abstract}

Keywords: synovial fluid, cartilage wear particles, joint disease, articular cartilage, arthritis, osteochondritis dissecans, horse

\begin{abstract}
Knorpelabriebprodukte in der Synovia beim Pferd und ihre Beziehung zu verschiedenen Gelenkerkrankungen
Lahmheit ist eine der Hauptursachen für Schmerzen und Unwohlsein bei Pferden und führt zu finanziellen Verlusten bei den Besitzern. Die Frühdiagnose von Gelenkerkrankungen, insbesondere degenerative Gelenkerkrankungen, stellt für Tierärzte eine große Herausforderung dar. Eine Untersuchung der Synovia auf Knorpelfragmente könnte einen Gelenkknorpelschaden frühzeitig nachweisen. Das Hauptziel dieser Studie war ein Bezug zwischen Zahl und Größe der Knorpelabriebprodukte zu Lahmheit bei verschiedenen Gelenkerkrankungen nachzuweisen. Insgesamt wurden 116 Gelenke (Huf-, Fessel-, Vorderfußwurzel-, Sprung- und Kniegelenk) von 67 Pferden, die zwischen 2 Monaten und 23 Jahre alt waren, punktiert und auf die Anzahl und Größe von Knorpelabriebprodukte hinuntersucht. Die Proben wurden 15 Minuten zentrifugiert und anschließend mikroskopisch ausgewertet. Bei den Pferden wurden verschiedene Gelenkerkrankungen diagnostiziert und anhand klinischer, röntgenologischer und arthroskopischer Befunde in 6 Gruppen geteilt. Bei Pferden mit Arthrose und Osteochondrosis dissecans konnte ein signifikanter Zusammenhang zwischen Knorpelrückstand in der Synovia und der Schädigung der Gelenkoberfläche festgestellt werden. Bei akuten Fällen, wie zum Beispiel in Synovia von Pferden mit septischer Arthritis, konnte ein derartiger Zusammenhang nicht nachgewiesen werden. Die Untersuchung auf Knorpelabriebprodukte in der Synovia stellt bezüglich Prognosestellung und Therapieansatz eine einfache minimalinvasive Methode zur besseren Einschätzung eines Fortschreitens degenerativer Gelenkerkrankungen dar.
\end{abstract}

Schlüsselwörter: Synovia, Knorpelabriebprodukte, degenerative Gelenkerkrankungen, Gelenkknorpel, Arthrosis, Osteochondrosis dissecans, Pferd

\section{Introduction}

Lameness is a major source of pain and distress to the horse and a financial loss to the owner. Joint injury and joint disorders represent a major part of the equine practitioners workload and, in the majority of cases, cartilage failure has been identified as an important contributing factor (Todhunter and Lust 1990, Trotter and Mcllwraith 1996). Most joint lesions are caused by chronic fatigue of the joint structure in which the rate of micro damage exceeds the rate of repair, especially where the amount of cartilage is extraordinarily low (Pool 1996). Lesions to the articular surfaces often occur secondary to a variety of joint diseases and present difficult diagnostic problems both in veterinary and human medicine.

It is not possible to make an accurate prediction of the state of a joint by assessing articular cartilage simply through radiology, as osteoarthritic deterioration begins long before a radiological diagnosis can be made. Arthroscopy still seems to be the most sensitive technique in the evaluation of osteoarthritis. The establishment of a precise prognosis without surgical intervention is especially difficult (Chan et al. 1991, Fife et al. 1991, Ike 1993, Blackburn at al. 1994). Developing effective methods that enable an early detection of cartilage injury or degeneration in an affected joint is therefore of paramount importance.

Several researchers have suggested that the principles of particle wear analysis may provide a means of assessing the functional integrity of articular surfaces, as well as identifying lesions or deterioration of the articular cartilage (Mears et al. 1978, Evans et al. 1980). The pathological changes associated with arthrosies and a number of diverse joint diseases in both humans and animals have shown to produce significant debris within the joint capsule cavity (van Pelt 1974, Yehia and Duncan (1975). Is has been suggested that the presence 
and morphology of such fragments can be possible indicators of the extent of articular damage (Muirden 1970, Tew 1980).

Ferrographic analysis, a technique which was originally developed to analyse wear in machines (Scott et al. 1974), has shown an interesting correlation between cartilage damage and cartilage particles in human joints (Evans et al. 1981, 1982). Fractual methods have been applied to characterize the complexity of these wear particles (Kirk and Stachowiak 1991, Hamblim and Stachowiak 1993, Podsiadlo and Stakowiak 1995). The shapes of these fragments were also analysed and compared with the osteoarthritic status of findings in human knee joints (Kuster et al. 1998).

The aim of this study was not only to verify if the number and size of cartilage fragments correlating with different joint diseases (in the case of lame and/or healthy horses) but also to develop a simple method that could eventually be used as a diagnostic tool.

\section{Materials and Methods}

A total of 116 samples of synovial fluid from 67 horses, between 2 months and 23 years old, were examined to determine the presence of cartilage debris. Animals were chosen based on the casuistic of the Equine Clinic of the Freie Universität Berlin and the diagnosis of specific articular problems. As much synovial fluid as possible was withdrawn from different joints (coffin, fetlock, carpus, tarsus and stifle joint), with a 12-gauge needle, by arthrocentesis, during the examination or the arthroscopy. The fluid was then placed in heparin-coated vacutainers.

Other common synovial fluid analyses were also made: appearance (colour, degree of opacity, presence of flocculent material and viscosity), clot formation, cytological properties (total erythrocyte and leukocyte counts) and protein content.

Samples were centrifuged at $3000 \mathrm{rpm}$ for 15 minutes. A Neubaver camera was prepared with the sediment. Cartilage particles were then analysed and quantified microscopicallyin the microscope. The cartilage wear particles were counted in each slide and each slide was prepared with $20 \mu \mathrm{L}$ of the sediment of the sample after centrifugation.

The groups were divided into "Control" (C), non-lame horses and "Test" $(T)$, lame horses. These two main groups were subdivided into:
- C1: no clinical signs, without radiography

- C2: no clinical signs, without radiographic alterations

- C3: no clinical signs, with radiographic alterations

- T1: lame horses, without radiographic alterations

- T2: lame horses, with radiographic alterations

- T3: lame horses, with radiographic and arthroscopic alterations

A summary with the characteristics of the groups can be found in table 1 .

The horses were diagnosed with osteochondritis dissecans (OCD), navicular syndrome (NS), infectious arthritis (IA), osteoarthritis (OA) and Podarthritis (PO). Diagnoseis were based on clinical examination, radiographic and arthroscopic features. An aid in the diagnosis of podarthritis and navicular syndrome was the direct manometry in the coffin joint, according to Hertsch and Höppner 1999. For the classification of horses as lame or as non-lame, diagnostic anaesthesia was done in all cases. For the statistical analyses one-way ANOVA and Student's t tests were used, with the level of significance set at $p<0.05$.

\section{Results}

The samples were collected from 116 joints: 28 from sound joints, 8 from horses with infectious arthritis, 26 from patients with osteochondritis dissecans (OCD), 15 from osteoarthritic joints, 36 from animals with navicular syndrome, and 3 from horses with podarthritis. The cartilage wear debris found had a length between 20 and $200 \mu \mathrm{m}$. They were then divided into small $(<40 \mu \mathrm{m})$, middle $(>40 \mu \mathrm{m}$ and $<60 \mu \mathrm{m})$ and big $(>60 \mu \mathrm{m})$ particles, as can be seen in the graphs.

Some particles were also found in control groups $\mathrm{C} 1$ and $\mathrm{C} 2$, but in significantly smaller quantity when compared to $\mathrm{C} 3$ and to "test" groups T2 and T3 (Figure 2). When comparing patients with only OCD and the control group, there was a significant increase in the number of cartilage fragments; even in horses that did not show clinical signs represented in group C3 (Figure 3). In synovial fluid samples from animals with the navicular disease, this increase was significant in groups C3 and T2 (Figure 4). Osteoarthritic joints also presented a significantly greater amount of small, average and large cartilage wear particles, as can be observed in figure 5 . The cartilage fragments appeared in different shapes, some of them can be seen in (Figure 1). Lamellar and elongated particles were found in all groups. Chunky cartilage wear

Table 1 Characteristics of the groups and average age of the horses. osteochondritis dissecans: OCD; navicular syndrome: NS; podarthritis: PO; infectious arthritis: IA; traumatic acute arthritis: TAA; osteoarthritis: OA. n: number of samples in each group

\begin{tabular}{|c|c|c|c|c|c|c|}
\hline Groups: $n$ & Lameness & $\begin{array}{c}\text { Radiographic } \\
\text { alterations }\end{array}$ & $\begin{array}{l}\text { Arthroscopic } \\
\text { alterations }\end{array}$ & \multicolumn{2}{|c|}{$\begin{array}{l}\text { Diagnosis: } \\
\text { Number of samples }\end{array}$} & Average age of the horses \\
\hline$C 1: 20$ & no & --- & --- & --- & & $12 \pm 2$ \\
\hline C2: 08 & no & no & --- & --- & & $9.8 \pm 1.4$ \\
\hline C3: 20 & no & yes & --- & OCD: 10 & NS: 10 & $9.4 \pm 2.1$ \\
\hline $\mathrm{T} 1: 11$ & yes & no & -- & IA: 8 & PO: 3 & $9.1 \pm 2.6$ \\
\hline T2: 29 & yes & yes & -- & $O A: 3$ & NS: 26 & $13.8 \pm 2.2$ \\
\hline T3: 28 & yes & yes & yes & OCD: 16 & OA: 12 & $9.4 \pm 1.6$ \\
\hline
\end{tabular}


debris only appeared in samples from horses that showed pain and radiographic alterations. There was no correlation between the presence or number of particles and other synovial fluid parameters analysed in synovial fluid, like viscosity, cell counts and protein content. Table 2 shows the relationship between age and the various different diagnoseis of
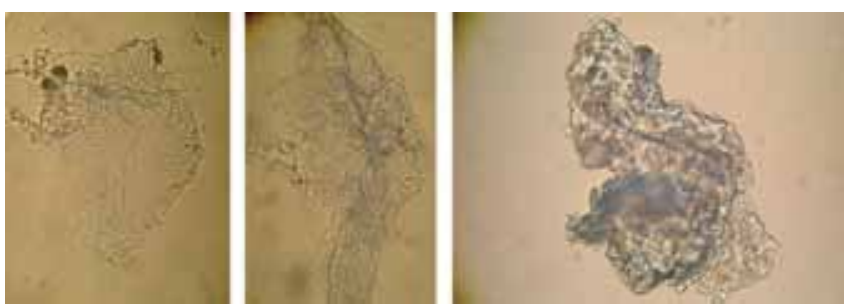

Fig 1 Different cartilage fragments isolated from synovial fluid. From left to right: lamellar, elongated and chunky shaped wear fragments (magnification x 200).

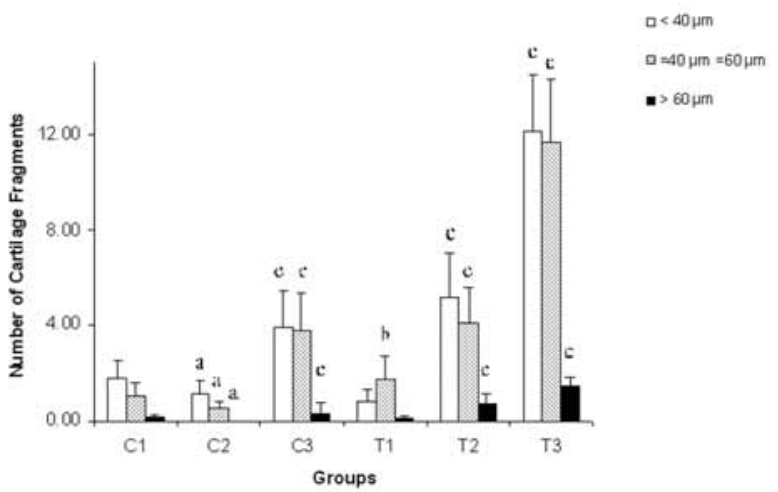

Fig 2 Number (per $20 \mu \mathrm{L}$ of synovial fluid) and size of cartilage fragments versus groups. a: $\mathrm{P}<0.05$ compared with the same length in control group $\mathrm{Cl} ; \mathrm{b}: \mathrm{P}<0.05$ compared with the same length in control group C2; c: P<0.05 compared with the same length in both $\mathrm{C} 1$ and $\mathrm{C} 2$.

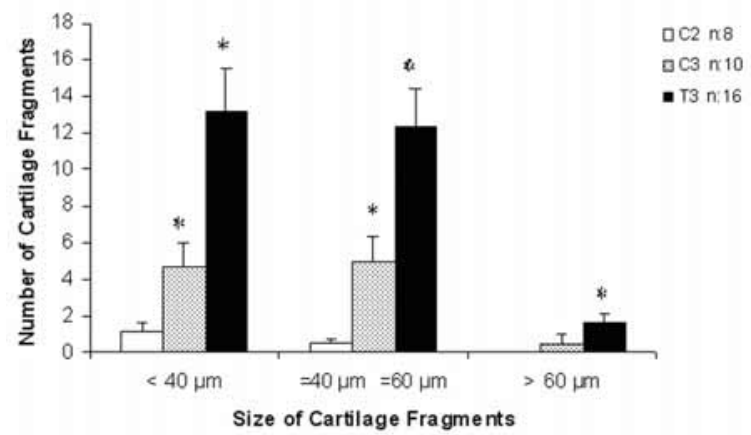

Fig 3 Number (per $20 \mu \mathrm{L}$ of synovial fluid) and size of cartilage fragments from the animals with osteochondritis dissecans. ${ }^{*} \mathrm{P}<0.05$ compared with the same length in control group C2. joint disease found in this study. Most of the animals were between 2 and 10 years old (41 horses). This group showed the greatest number of cartilage fragments. Thirty-seven horses were between 11 and 20 years old. There were also 5 patients younger than 1 year and 5 patients older than 21 years. The most common number of small, average and large cartilage particles was found in patients between 2 and 10 years old, as can be seen in table 3 . This is exactly the same age range as where we find most horses suffering from osteochondritis dissecans and where osteoarthritis is found.

\section{Discussion}

This data shows a significant increase in the number of cartilage fragments in osteoarthritic joints, as it was has been previously described in literature (Evans et al. 1981 and 1982, Kuster et al. 1998). The same was noticed in samples from horses with osteochondritis dissecans (OCD), which is in contrast with the study of Tew in 1980, where he rarely found large amounts of particles in the mentioned joints. In current

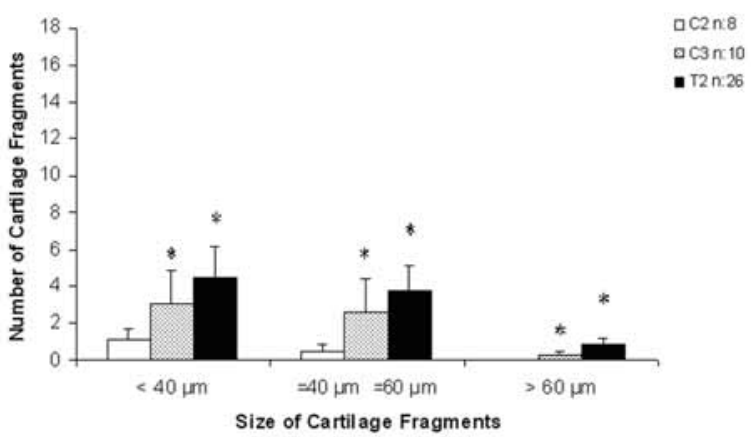

Fig 4 Number (per $20 \mu \mathrm{L}$ of synovial fluid) and size of cartilage fragments from the animals with navicular syndrome. ${ }^{*} \mathrm{P}<0.05 \mathrm{compa}-$ red with the same length in control group C2.

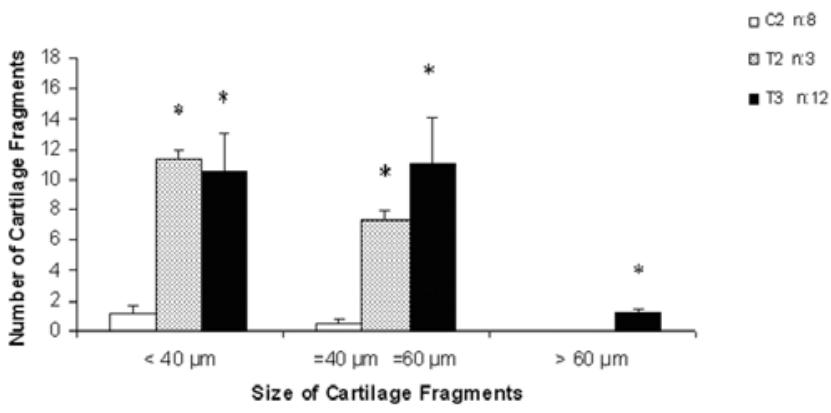

Fig 5 Number (per $20 \mu \mathrm{L}$ of synovial fluid) and size of cartilage fragments from the animals with osteoarthritis. ${ }^{*} \mathrm{P}<0.05$ compared with the same length in control group C2.

Table 2 Relationship between the age of the horses and the various diagnoses of joint disease (osteochondritis dissecans: OCD; navicular syndrome: NS; infectious arthritis: IA; osteoarthritis: OA).

\begin{tabular}{|c|c|c|c|c|c|}
\hline Age of the horse & Number of samples & $O C D$ & NS & IA & OA \\
\hline 1 year old or younger & 5 & 1 & 1 & 3 & 0 \\
\hline Between 2 and 10 years old & 41 & 16 & 12 & 3 & 10 \\
\hline Between 11 and 20 years old & 37 & 9 & 21 & 2 & 5 \\
\hline Older than 21 years & 5 & 0 & 5 & 0 & 0 \\
\hline Total & 88 & 26 & 39 & 8 & 15 \\
\hline
\end{tabular}


Table 3 Age of the patients and its relationship with the amount and size (small: $<40 \mu \mathrm{m}$, middle: $\geq 40 \mu \mathrm{m}$ and $\leq 60 \mu \mathrm{m}$ and big: $>60 \mu \mathrm{m}$ ) of cartilage fragments found in synovial fluid. Results are expressed as means \pm S.E.M

\begin{tabular}{|c|c|c|c|c|}
\hline Joint & Number of samples & $<40 \mu \mathrm{m}$ & $\geq 40 \mu \mathrm{m}$ and $\leq 60 \mu \mathrm{m}$ & $>60 \mu \mathrm{m}$ \\
\hline 1 year old or younger & 5 & $2.4 \pm 1.4$ & $3 \pm 2.3$ & $0.2 \pm 0.2$ \\
\hline Between 2 and 10 years old & 41 & $9 \pm 2.8$ & $8.6 \pm 2.9$ & $1.0 \pm 0.5$ \\
\hline Between 11 and 20 years old & 37 & $4.7 \pm 1.9$ & $4.0 \pm 1.6$ & $0.6 \pm 0.4$ \\
\hline Older than 21 years & 5 & $3.6 \pm 0.8$ & $3.8 \pm 0.8$ & $0.4 \pm 0.2$ \\
\hline Total & 88 & & & \\
\hline
\end{tabular}

research these animals have also shown a correlation between pain and the amount of fragments, as can be seen in figure 3. It has been noted in literature that in patients with OCD significant damage only occurs when the chip lies between articular surfaces (Tew 1980), as in this position. This is also when it would probably cause pain. However, our results indicate that even when there are no clinical signs, there may already be cartilage micro damage. Incipient cartilage lesions do not cause pain, which is a potential reason for delayed detection of articular cartilage damage (Woitys et al. 1990). Little is known about the fate of these fragments arising from articular cartilage, presumably they are eventually degraded or absorbed. However, there is evidence to suggest that, once produced, they would remain in the synovial fluid for at least some weeks (Tew and Hackett 1981).

Patients diagnosed with navicular syndrome in group C3 were horses in the chronic stage of this disease. These animals were pain-free, although the intra-articular pressure was still high and they were therefore still in treatment. Acute cases of joint disease can be seen in figure 2, group $\mathrm{T1}$, where patients with infectious arthritis are included. There were no significantly increased numbers of fragments in these samples. This is, in contrast with the study from Tew 1980, where $65 \%$ of acute cases showed a great quantity of cartilage wear particles. However, in both studies there was no correlation between the characteristics of effusion, or protein concentration and the number of cartilage fragments.

Like other authors, we have also found cartilage wear particles in healthy, or at least apparently healthy joints (Evans et al. 1982, Kuster et al. 1998). Our control group C1, where no radiographies were taken, showed a greater number of particles than group C2, without radiographic alterations. For this reason we decided to use C2 as a control in the last three graphics (figure 3, 4 and 5). There were particles even greater than $60 \mu \mathrm{m}$ in $\mathrm{Cl}$, although few, which was not seen in C2. However, Kuster and colleagues in 1998 also found particles ranging from 13.6 and to $97.4 \mu \mathrm{m}$ (average $37.6 \mu \mathrm{m}$ ) in healthy joints, which is very similar to the results of the current study.

An important point to consider is whether it is normal to find these fragments in sound joints, more specifically in those submitted to high loads, or whether increased amounts of fragments already represent micro damage, so small it that cannot be discovered by arthroscopy, as proposed by Evans in 1982. In 1980, Tew suggested that biomechanically sound joints would not produce any significant number of cartilage wear particles when placed under normal stress, whereas impaired cartilage could be expected to produce wear debris, even under normal stress (Tew and Hackett 1981). According to these authors, the absence of cartilage particles in joint fluid could be equally as important as the presence of particles in the accurate diagnosis of the cause of lameness.

The age range in this study was quite large. The group between 2 and 10 years old showed the greater number of cartilage fragments, whereas animals older than 20 years showed not as many particles. It can be observed that this diagnosis played a more important role than age. Osteoarthritic joints presented the greatest number of particles and they were exactly more prevalent in this study in patients between 2 and 10 years old.

The articular cartilage is divided into 4 anatomic zones. The thin tangential or superficial layer, in contact with the synovial fluid, is only a few microns thick and contains small and flat chondrocytes. Immediately below is the transitional zone, characterized by larger and more rounded cell profiles. In the radiate zone, the cells are larger and arranged with their long axis perpendicular to the surface. The deepest layer of cartilage is continuous with the calcified tissue (Mcl/wraith and Trotter 1996).

Several authors have tried to correlate the quality of cartilage wear particles with the respective zone. Based on the characteristics of the cells, Tew in 1980 found small fragments in acute cases, which appeared microscopically as non-cellular flakes and he concluded they should have come from superficial and resting layers. In cases of chronic lameness, the fragments were thought to originate from deeper layers. Tew $\mathrm{He}$ also found particles originating from deep layers and the subchondral bone in patients with OCD. As we did not stain the fragments, it was impossible to identify the cells and therefore, the zone of origin.

Other researchers have proved the relationship between the shape of the wear particles and the extent of articular cartilage damage. They then correlated these findings with the most probable zone. Lamellar, leaf wear particles were found in healthy joints should have come from the lamina splendens. Damage in the tangential zone would probably results in originate elongated, rod-shaped particles and deep cartilage zone damage would produce chunky fragments (Kuster et al. 1998).

In the present study all these shapes of particles were found. Lamellar and elongated fragments appeared in all 6 groups, but chunky particles were only seen in synovial fluid from horses that showed pain and radiographic alterations. However, it was possible to identify other varieties of shapes as well. This is a very subjective analysis and for some particles the visual differentiation might be difficult, due to the fact that wear fragments can exhibit similar morphology. 
In the development of this technique, costly and time-consuming analytic methods were avoided to make the overall analysis practical for routine use. The basis of histologic identification of cartilage wear debris can be demonstrated using artificially generated particles of articular cartilage. Not staining the fragments has limited the research, because it was not possible to study the cells. There are potential artefacts that might be confounded with cartilage particles. However, when performed by an experienced observer, this simple minimal invasive method could allow an early assessment of cartilage micro damage in osteoarthritis and other joint diseases, which could lead to osteoarthritis. Further studies should be performed, because this technique shows potential to provide a great assessment of degenerative joint disease progress, long-term prognosis and evaluation of therapeutic regimes at any time point in the process, without repeated surgical intervention.

\section{Acknowledgments}

This study was supported by CAPES (Coordenação de Aperfeiçoamento de Pessoal de Nível Superior - "bolsista CAPES - Brasília/Brasil") and DAAD (Deutscher Akademischer Austauschdienst / German Academic Exchange Service).

\section{References}

Blackburn W. D., Bernreuter W. K. and Rominger M. (1994) Arthroscopic evaluation of knee articular cartilage: a comparison with plain radiographs and magnetic resonance imaging. J. Rheumatol. 21, 675-679

Chan W. P., Lang P. and Stevens M. P. (1991) Osteoarthritis of the knee: Comparison of radiography, CT, and MR imaging to assess extent and severity. Am. J. Roentgenol. 157, 799

Evans C. H., Bowen E. R., Bowen J., Tew W. P. and Westcott V. C. (1980) Synovial fluid analysis by ferrography. J. Biochem. Biophys. Methods 2, 11-81

Evans C. H., Mears D. C. and McKnight J. L. (1981) Preliminary ferrographic survey of wear particles in human synovial fluid. Arthritis Rheum. 24. 912-918

Evans C. H., Mears D. C. and Stanitski C. L. (1982) Ferrographic analysis of wear in human joints. The journal of bone and joint surgery 64, 572-578

Fife R. S., Brandt K. D. and Braunstein E. M. (1991) Relationship between arthroscopic evidence of joint space narrowing in early osteoarthritis of the knee. Arthritis Rheum 69, 302-312

Hamblin M. G. and Stachowiak G. W. (1993) Comparison of boundary fractal dimensions from projected and sectioned particle images. Part I - Technique evaluation. J. Comput. Assist. Microsc. 5, $291-300$
Hertsch B. and Höppner S. (1999) Zur Diagnostik des Podotrochlose-Syndroms in der Praxis. Pferdeheilkunde 15, 294-308

Ike R. W. (1993) The role of arthroscopy in the differential diagnosis of osteoarthritis of the knee. Rheum. Dis. Clin. North. Am. 19, 673-696

Kirk T. B. and Stachowiak G. W. (1991) Fractal computer image analysis applied to wear particles from arthritic and asymptomatic human joints. J. Orthop. Rheumatol. 4, 13-30

Kuster M. S., Podsiadlo P. und Stachowiak G. W. (1998) Shape of wear particles found in human knee joints and their relationship to osteoarthritis. British J. Rheumatol. 37, 978-984

Mcllwraith C. W. and Trotter G. W. (1996) Joint disease in the horse. Eds: W. B. Saunders Co., Philadeilphia

Mears D. C., Hanley E. N., Rutkowski R. and Westcott V. C. (1978) Ferrography: its application to the study of human joint wear. Wear 50,1 15-125

Muirden K. D. (1970) Giant cells, cartilage and bone fragments within rheumatoid synovial membrane. Aust. Ann. Med. 2,105-1 10

Podsiadlo P. and Stachowiak G. W. (1995) Median-sigma filter for SEM wear particle images. J. Comput. Assist. Microsc. 7, 67-82

Pool R. R. (1996) Pathologic manifestations of joint disease in the athletic horse. In: Joint disease in the horse, Eds: C.W. Mcllwraith and G.W. Trotter, W. B. Saunders Co., Philadelphia. 87-104

Scott D., Seifert W. W. and Westcott V. C. (1974) The particles of wear. Sci. Amer. 230, 88-97

Tew W. P. (1980) Synovial fluid particle analysis in equine joint disease. Mod. Vet. Pract. 993-995

Tew W. P. and Hackett R. P. (1981) Identification of cartilage wear fragments in synovial fluid from equine joints. Arthritis Rheum. 24, 1419-1424

Todhunter R. J. and Lust G. (1990) Pathophysiology of synovitis: clinical signs and examination in horses. Comp. Cont. Educ. Pract. Vet. 12, 980

Trotter G. W. and Mcllwraith C. W. (1996) Advances in equine arthroscopy. Vet. Clin. N. Am.: Equine Pract. 12, 261

van Pelt R. W. (1974) Interpretation of synovial fluid in the horse. J. Am. Vet. Med. Assoc. 165, 91-95

Woitys E. M., Beaman D. N. and Glover R. A. (1990) Innervation of the human knee joint by substance-P fibers. J. Arthroscop. Rel. Surg. 6, 254-263

Yehia S. R. and Duncan H. (1975) Synovial fluid analysis. Clin. Orthop. 107, 11-24

Dr. Ticiana Meireles Sousa

Klinik für Pferde, Allgemeine Chirurgie und Radiologie

Freie Universität Berlin

Oertzenweg $19 \mathrm{~b}$

14163 Berlin

ticianameireles@yahoo.com.br 